\title{
Entre pinceles y libros: textos para un enfoque intertextual e interdisciplinar en el aula de lengua'
}

\author{
Among brushes and books: texts for a intertextual and interdisciplinary \\ approach in the language classroom
}

\author{
Ma DEL CARMEN QUILES CABRERA \\ Universidad de Almería \\ España \\ qcabrera@ual.es
}

Resumen. El presente artículo realiza un aproximación al tratamiento de la pintura y la literatura en clase de lengua. Pondremos de manifiesto cómo la conexión intertextual, presente en las manifestaciones estéticas, puede resultar una vía de actuación docente al servicio de la adquisición de lenguas. De este modo, detallamos una propuesta de trabajo que perfila varias líneas de aplicación al aula.

Palabras clave: literatura; intertextualidad; interdisciplinariedad; lengua; didáctica.
Abstract. This article makes an approach to the study of painting and literature in language lessons. We will show how the intertextual connection, present in the aesthetic expressions, can become part of a teaching process to favour the acquisition of languages. Thus, we provide a proposal of work dealing with several teaching and learning procedures in the classroom.

Key words: literature; intertextuality; interdisciplinariety; language; didactic.

\footnotetext{
${ }^{\text {I }}$ Para citar este artículo: Quiles Cabrera, M.C. (2OI2). Entre pinceles y libros: textos para un enfoque intertextual e interdisciplinar en el aula de lengua. Alabe 6. [www.revistaalabe.com]

(Recibido 27-O3-2OI2; aceptado OI-IO-2OI2)
} 


\section{Aprender una lengua y su cultura}

Aproximarnos a una lengua, más allá del acceso a un código determinado, supone adentrarnos en el entramado cultural sobre el que se sustenta; un entramado que rige, en cierta medida, los usos comunicativos de sus hablantes. Cuando adquirimos un idioma, recorremos un camino que nos lleva desde su gramática a las pautas y las convenciones sociales que condicionan sus usos; los saludos, las despedidas, los aspectos relacionados con la cortesía verbal, entre otros, son entendidos de forma distinta entre unas colectividades y otras, lo cual se refleja directamente en cómo emplean el lenguaje. Del mismo modo, entrar en contacto con sus manifestaciones artísticas -su literatura, su pintura, su música, su folclore- nos abrirá una puerta para conocer su historia, su forma de pensar y de concebir el mundo. Compartir una misma lengua no es sólo manejar un mismo código, sino participar de un mismo imaginario cultural.

Cuando hablamos de lengua solemos pensar en un código al que los hablantes han de rendirse cuando hacen uso de él para interaccionar con sus semejantes. Parece que los idiomas hubieran sido creados por alguien ajeno al mundo para que el hombre acatara sus órdenes; sin embargo, olvidamos que son las lenguas las que están al servicio del hombre y no a la inversa, porque fueron las comunidades parlantes quienes las crearon para su funcionalidad. Aprender un idioma no implica exclusivamente el aprendizaje de una serie de etiquetas para designar las cosas, sino que supone entender todo el engranaje social en que dicho código lingüístico se ha gestado. En el contexto materno, la lengua supone una de las primeras señas de identidad, unida a las tradiciones, el folclore, el arte, etc.

La relación lengua y cultura ha sido una cuestión tomada muy en cuenta en el ámbito de la enseñanza de idiomas extranjeros (Miquel, I997; Vez, 2OOO; Martinell et al., 2004; Ambadiang y García, 2006; Olalla y Úcar, 20Iо). Sin embargo, es momento de rescatar dicha apreciación en el contexto de la didáctica de la lengua materna (Muñoz, 2OII), puesto que el componente social, histórico, cultural o artístico no se adquiere de forma espontánea. Cuando un hablante nativo mantiene prejuicios sociales ante determinadas modalidades de lengua o no es capaz de reconocer sus principales referentes literarios, musicales, folclóricos, etc., tiene todavía un camino largo por recorrer hasta lograr una competencia comunicativa plena.

Con la llegada de la LOGSE los diseños curriculares hablaron de la diferencia entre conocer y dominar una lengua determinada, junto al refuerzo de las identidades propias de cada comunidad; las hablas andaluzas, por ejemplo, reciben un tratamiento mucho más avanzado en los diseños oficiales, al entenderse como modalidades de habla, frente a la visión negativa con que se habían presentado los fenómenos dialectales en la Ley de r970. Los nuevos paradigmas para el área educativa de Lengua y Literatura de los noventa se han mantenido y reforzado en la Ley Orgánica de Educación (L.O.E) de 2006, que regula en la actualidad la aplicación de las enseñanzas. Dicha ley indica para nuestra área la necesidad de desarrollar las cuatro habilidades lingüísticas básicas: escu- 
char, hablar, leer y escribir. La enseñanza de la lengua ha de pasar de enseñar a conocer un sistema de normas -la gramática o código- a enseñar a dominar una lengua viva en constante movimiento, porque es la única forma de ayudar a los estudiantes a desarrollar su competencia comunicativa (Hymes, I962 y r97ı; Cassany, r994; Mendoza, López y Martos, I996).

\section{Interdisciplinariedad e intertextualidad en el aula}

La idea precedente enlaza con el papel educativo de la interdisciplinariedad. El aprendizaje significativo de Ausubel y la concepción cíclica del currículo en las enseñanzas medias hacen ver el trabajo interdisciplinar como una de las alternativas más ricas para la escuela actual. El concepto de interdisciplinariedad, abordado desde una perspectiva educativa, se gesta hace algún tiempo; en I986 se celebraron en Alicante las Jornadas de la Interdisciplinariedad y en la década de los noventa el concepto continuó tratándose con interés (Larrosa, I990; Torres, ı994; Ander-Egg, ı996; López-Barajas, ı997; Bastons et. al., I997). En los últimos años, se ha seguido hablando del término a partir de la idea de integración, de globalización y de desarrollo de competencias (Guerra, 2003; Delgado, 2009; Muhsin, 2009). Y, en esta dirección, las distintas áreas de conocimiento se presentan como grandes aliadas en favor de una aproximación rica a la lengua propia de los aprendices y, con ella, a su cultura y a sus manifestaciones artísticas.

Las directrices curriculares de nuestro actual sistema educativo, al que ya nos hemos referido, reconocen que el proceso de enseñanza-aprendizaje de la lengua ha de lograrse a través de un enfoque funcional, de un acercamiento al mundo de la literatura infantil y juvenil y de un uso reflexivo de las lenguas. Además, no se considera ésta una misión exclusiva del profesor de lenguas, sino que advierte de la necesidad de una implicación de toda la comunidad educativa. La literatura, el cine o la música, por su parte, nos aportan testimonios escritos y orales de modelos lingüísticos muy diversos que nos dan pie a trabajar múltiples competencias; por otro lado, los textos pictóricos, en tanto que documentos icónicos, se convierten en la base sobre la que propiciar distintas situaciones de comunicación ante los aprendices, de forma que vamos a potenciar el desarrollo de su lengua a la vez que conocerán un momento histórico, un conflicto social o un movimiento artístico.

Por otro lado, hemos de hablar también de intertextualidad, concepto acuñado por Bajín y heredado por Julia Kristeva (I98I). Podemos decir que "El término intertextual hace referencia a una relación de reciprocidad entre los textos, es decir, a una relación entre-ellos, en un espacio de trasciende el texto como unidad cerrada" (Villalobos, 2003: I37). Esa conexión intertextual está presente no sólo en los textos literarios, sino en los textos propios de otras artes; incluso traspasa unas y otras (Mendoza, 200o; Caro, I996; Martínez, 20oI; Abbate, 2002; Lara, 2007; Camarero, 2008), lo cual establece también un vínculo entre disciplinas. 
A la búsqueda de manifestaciones que nos permitan trabajar la intertextualidad en el aula de lengua, podríamos volver la vista a muy diversos testimonios que, además, nos permitirían abordar el aspecto interdisciplinar, como se recomienda en los actuales parámetros curriculares. Temas como "la luna", "los piratas" o "las sirenas" han colmado las páginas de muchas producciones literarias, al tiempo que se han recreado en canciones u obras pictóricas (Quiles, 2OIO); incluso la mitología clásica supone otra fuente inagotable de diálogos entre textos de distintas ramas artísticas (Moormann y Uitterhoeve, 1997), así como los cuentos de hadas se han reformulado de muy diversos modos a lo largo del tiempo.

Este carácter intertextual de los textos artísticos se convierte en un fenómeno de gran utilidad en el ámbito de la educación lingüística y literaria, se trate de una lengua primera, segunda o extranjera, especialmente cuando el docente sea capaz de buscar conexiones, de establecer puentes que permitan ponerlos al servicio del aprendizaje. De esta forma, el aprendiz entraría en contacto con elementos culturales y estéticos -el arte, se enfrentaría a distintas situaciones de comunicación hablada y escrita - la interacción- y además se combinarían fuentes documentales de diversos ámbitos. En este sentido, propuestas como la que planteamos en esta ocasión requieren de una complicidad entre el profesorado encargado de las distintas materias, para que exista una auténtica interdisciplinariedad; cuando los materiales son compartidos en disciplinas distintas y los estudiantes están abordando un mismo contenido desde dos perspectivas diferentes, el aprendizaje es mucho más significativo y podemos decir realmente que estamos atendiendo a un principio interdisciplinar ${ }^{2}$.

\section{Velázquez, Murillo y Goya: del lienzo al papel}

En esta ocasión proponemos detenernos en tres de los grandes autores de la pintura española. Nos estamos refiriendo Velázquez, Goya y Murillo. Por un lado, Las Meninas, que plasma el retrato de la hija de Felipe IV junto a sus damas de compañía y sus bufones. Con ese guiño realizado por el propio autor hacia sí mismo, se toma como inspiración para la creación de otras muchas obras que pretendido recrear esa imagen barroca desde muy distintos puntos de vista. Su paralelo por antonomasia lo encontramos en la pintura del siglo XX en la figura de Pablo Picasso, en quien encontramos su recuperación más evidente; sin embargo, no será ésta la única parada que hemos de realizar, puesto que, dejando a un lado a otros pintores contemporáneos ${ }^{3}$, la literatura nos ofrece testimonios de gran importancia en este sentido. Podríamos hablar de varios títulos que nos remontan a la obra y la persona de Velázquez, de modo que se nos crea un marco amplio de conexión intertextual e interdisciplinar:

\footnotetext{
${ }^{2}$ Una experiencia interesante de trabajo interdisciplinar entre la literatura y la música se recoge en Quiles (20o8).

3 Mencionaremos a los valencianos Manuel Valdés y Rafael Solves, que las han reinterpretado también en pintura.
} 


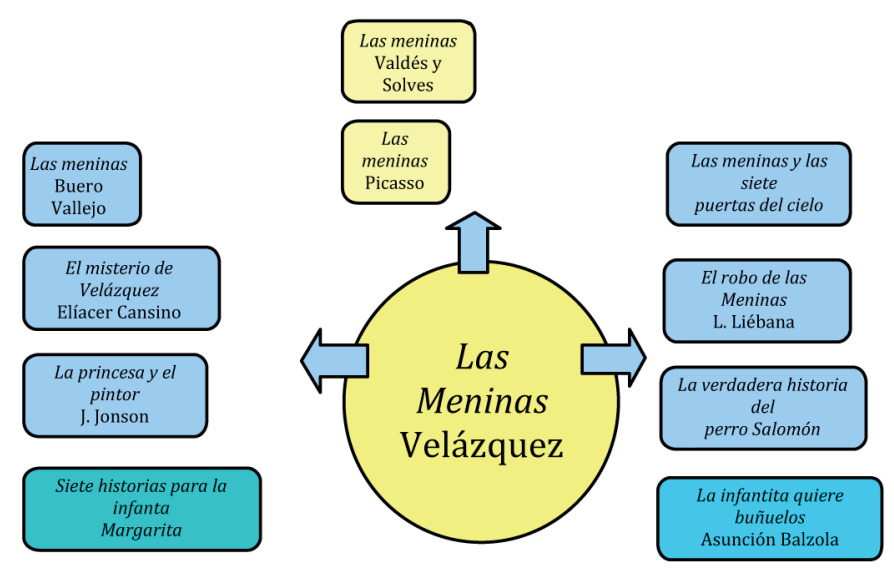

Figura 1

De todos los textos incluidos en el esquema previo, para nuestra propuesta hemos seleccionado dos de ellos. Por un lado, el titulado Siete historias para la infanta Margarita, del escritor Miguel Ángel Fernández Pacheco (200I), uno de los referentes esenciales de nuestra literatura infantil y juvenil actual. Este texto nos dará la pauta para iniciar el trabajo intertextual e interdisciplinar en el aula. Y, por otro lado, tomamos también como referencia la obra La infantita quiere buñuelos, cuya autora, Asunción Balzola (2003), ha sido una de las figuras consagradas en este mismo ámbito, tanto en su faceta de escritora como de ilustradora. La elección de este título viene motivada, además, por pertenecer a una colección de relatos cuya pretensión es acercar a los pequeños lectores a la pintura española. Tres cuadros -de Velázquez, Goya y Murillo- sirven de motivo literario; podemos decir que son tres imágenes que la autora toma como lo que se ha llamado hipotexto, esto es, el referente del que parten las recreaciones posteriores (Genette, I989). Los textos son los siguientes:

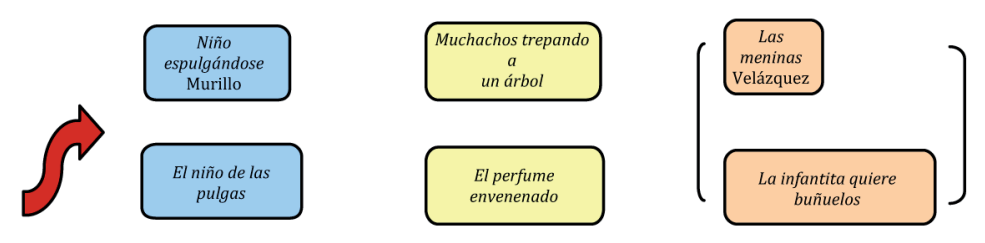

Figura 2 
Como sabemos, los tres cuadros retratan tres modelos distintos de niño: el nacido noble, el nacido en el pueblo y el nacido en la miseria; será ésta una cuestión que también nos permitirá introducir los temas transversales, la educación en valores y la creación de una conciencia crítica sobre los problemas sociales ${ }^{4}$. En La infantita quiere buñuelos, cobran vida los personajes del cuadro de Velázquez, que narran diversas historias para combatir el aburrimiento de la protagonista en las sesiones con el pintor. El Niño de las pulgas cuenta en primera persona el devenir de la vida de ese mendigo que es retratado por Murillo. Por su parte, El perfume envenenado teje una historia protagonizada por los niños del retrato y el propio Goya en torno a una trama de conspiración.

\section{I.- Planificación de la propuesta}

Muchos han sido los trabajos dedicados al factor intertextual (Dadson y Flitter, I998; Durañona, 2oo6; García, ı996; Martínez, 2oor; Mendoza, 2ooo; Mendoza y Cerrillo, 2003) e incluso a la conexión entre ambas artes (Hansen, r998; África y Claramente, I992; Rubio, 2006). Ahora bien, lo que pretendemos es perfilar distintas líneas de trabajo que, además de ir presididas por un enfoque interdisciplinar, integren la literatura infantil y juvenil en el proceso de desarrollo de las habilidades comunicativas. Hemos de entenderla desde una perspectiva amplia, globalizadora y abierta a las exigencias de adaptación que presente cada grupo discente.

\section{I.I. El nivel, el tiempo y las finalidades educativas}

Trabajar en esta línea puede resultar de gran utilidad en tercer ciclo de Primaria y primer ciclo de la Educación Secundaria y puede estimarse el tiempo de una programación quincenal o de tres semanas -tomando en cuenta la necesidad de coordinación entre las materias implicadas-. Las finalidades educativas que pretendemos alcanzar con las líneas de trabajo perfiladas giran en torno a los siguientes puntos:

- Integrar la intertextualidad y la interdisciplinariedad en el aula de lengua

- Desarrollar las habilidades comunicativas orales y escritas a través del texto literario y pictórico

- Entrar en contacto con varias manifestaciones estéticas propias de la lengua española y su cultura

- Acercarnos a su contextualización social e histórica

- Emplear los textos literarios como puerta de acceso a la lengua, la cultura y la pintura

- Crear situaciones variadas de comunicación en el aula

- Reforzar las destrezas de elaboración discursiva formal en español

- Trabajar la dimensión sociocultural de la lengua

- Introducir la educación transversal en el aula de lengua

- Potenciar el aprendizaje autónomo

\footnotetext{
${ }^{4}$ Recordemos que Murillo cuenta además con otros retratos protagonizados por la infancia, como Niños comiendo melón, cuyas imágenes nos recuerdan también otros cuadros de Goya (Niños comiendo pastel).
} 


\section{I.2. EI nivel, el tiempo y las finalidades educativas \\ Primer Bloque de la propuesta \\ a) Leemos e imaginamos}

Comenzaremos con el gran grupo leyendo el capítulo "Aparece su Alteza”, del relato Siete historias para la infanta Margarita. Esta parte nos servirá como introducción a la unidad temática ${ }^{5}$ y nos ayudará a crear un clima de debate y reflexión en torno a ese fragmento de la historia, siempre que seamos capaces de orientarlo hacia el trabajo de las destrezas orales y escritas. Para ello, podemos entregar al alumnado una ficha con las cuestiones que se discutirán finalmente de forma hablada:

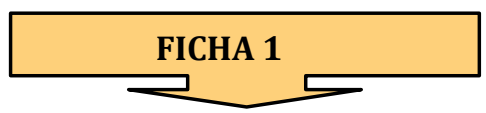

Hemos leído el fragmento de un relato titulado Siete historias para la Infanta Margarita, trata de responder a las siguientes cuestiones:

- ¿Dónde crees que se desarrolla la historia?

- ¿Quiénes piensas que son esos personajes?

- ¿Cómo te los imaginas? Describe a cada uno de ellos. Para ello has de tener en cuenta los siguientes datos:

- Edad

- Sexo

- Profesión / Dedicación

- Aspecto físico

- Personalidad

- Es importante usar marcadores discursivos y tener en

cuenta la coherencia de las ideas en la elaboración de la descripción.

Figura 4. Ficha 1 del estudiante

Podrán elaborar una guía escrita que les ayude a edificar su discurso una vez que, respetando los turnos de palabra, intervengan en el debate y lluvia de ideas oral, así como en el momento de presentarnos a sus personajes. Será importante, también, que justifiquen su descripción con el propio texto siempre que sea posible, de modo que al profesor le quede claro que el estudiante ha sabido interpretar el contenido, incluso en aquellos momentos en que no se aporta información explícita:

- En el caso de las descripciones físicas, el relato describe:

5 El relato de Elíacer Cansino, El misterio de Velázquez, puede resultar también un buen punto de partida para trabajar conjuntamente la aproximación al cuadro y el desarrollo de la competencia comunicativa en la lengua meta. 
- “despeinada, congestionada, jadeante, con el guardainfante torcido, la amplia falda arremangada de cualquier manera y una media caída (...)", "Sedosa melena, de rubio pajizo" (Pág. 25-26)

- Sin embargo, menos concretos son otros datos como los referentes al talante de los personajes, que hemos de deducir a partir de sus intervenciones o sus actos. Por ejemplo, podemos hablar de un Nicolasillo "chismoso", según las palabras de la protagonista:

- "Eso, a esas alturas, da igual. Los nombres me los dirá después Nicolasillo" (Pág. 29)

Así, podemos repartir entre los alumnos una ficha en la que traten de plasmar por escrito la justificación de su descripción personal en torno a cada personaje:

\begin{tabular}{|l|l|}
\hline Posibles interrogantes & Posibles respuestas \\
\hline La Infanta Margarita & \\
\hline ¿Por qué sabemos que es una niña? & $\begin{array}{l}\text { Porque se escuchan carcajadas infantiles, } \\
\text { corretea, aparece desaliñada,...(Pág. 25) } \\
\text { Porque se habla de su coquetería (Pág. 26) }\end{array}$ \\
\hline Don Diego & $\begin{array}{l}\text { Porque se dice que "levantó la mano con } \\
\text { la que pintaba" (Pág. 27) }\end{array}$ \\
\hline ¿Por qué te has imaginado que es un pintor? & $\begin{array}{l}\text { Porque se nos habla de que salta para } \\
\text { hacer la reverencia y en las palabras de la } \\
\text { Infanta se deja ver que él le contará el } \\
\text { chismosolasillo / Nicolás Pertusato }\end{array}$ \\
\hline $\begin{array}{l}\text { ¿Por qué pensamos que es divertido, alocado que nadie quiere hablarle. } \\
\text { (Págs. 28-29) }\end{array}$ \\
\hline sereno, frente a los perrillos falderos?
\end{tabular}


Toda esta tarea conlleva por parte del aprendiz el desarrollo de una serie de habilidades que oscilan desde la mera adquisición de léxico, hasta la dimensión sociocultural de dichos vocablos y la lectura crítica e interpretativa. Un buen ejemplo de ello lo tenemos, precisamente, en la locución "perrillo faldero", cuyo sentido se extiende en el registro coloquial a una connotación peyorativa referida a las personas.

\section{b) El encuentro con Velázquez y sus Meninas}

A continuación, les plantearemos a los estudiantes lo que en principio pensarán que es una hipótesis:

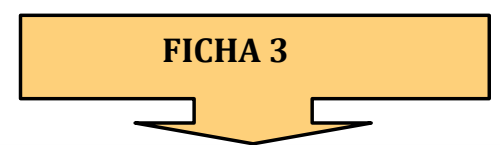

Y si se tratara de una historia basada en un cuadro... ¿Cómo sería esa imagen? Píntala.

Figura 6. Ficha 3 del estudiante

Una vez que lo hayan hecho, de forma voluntaria se irán explicando y mostrando los distintos dibujos. El siguiente esquema les servirá de guía:

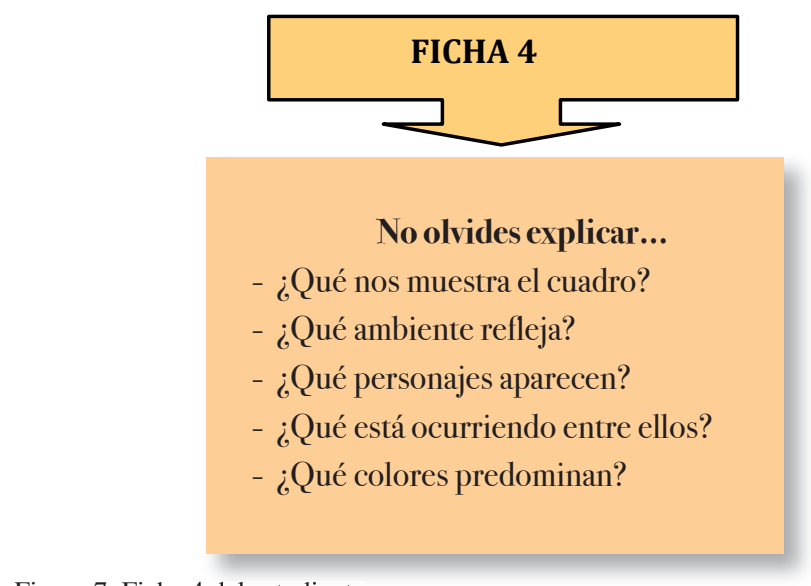

Figura 7. Ficha 4 del estudiante

Realizada esta tarea, les mostraremos el cuadro de Velázquez y volveremos a establecer un debate sobre sus impresiones ante la complicidad entre la pintura y el texto literario: 

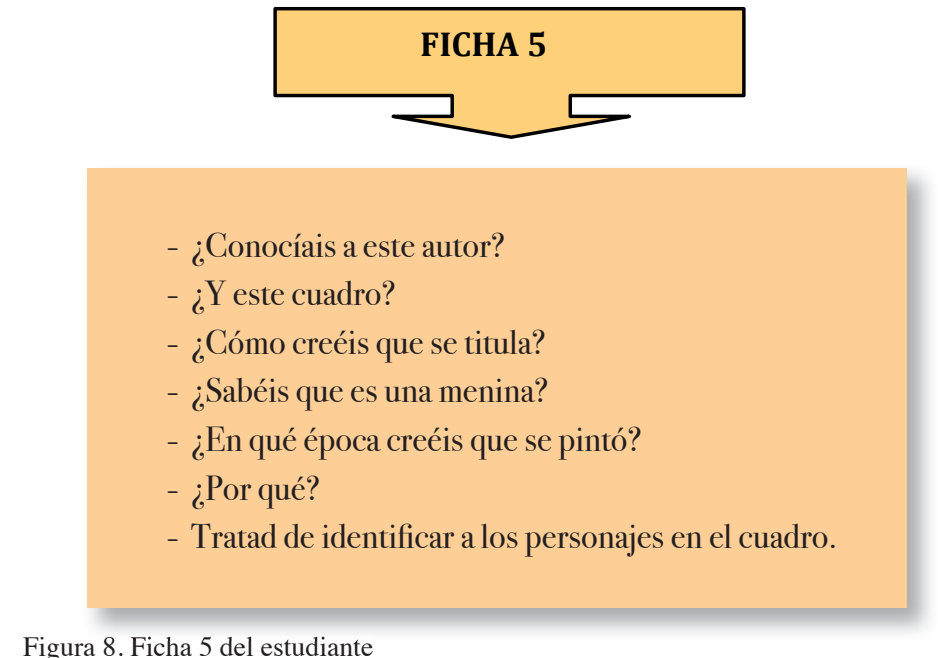

Figura 8. Ficha 5 del estudiante

El profesor guiará las intervenciones y les ayudará a situar la obra en su época y su contexto histórico, para hacer una primera aproximación y los orientará hasta ubicar de forma adecuada a cada uno de los personajes del cuadro, explicando de quién se trata y cuál es su papel en la Corte. El texto de Fernández Pacheco y su lectura interpretativa nos ha dado claves muy importantes en esta línea. En esta tarea resulta importante que favorezcamos el uso de estrategias relacionadas con la coherencia, la buena ilación y disposición del discurso.

Será el momento, entonces, de indagar en la figura del "bufón”, la "menina” y "el guardadamas”, términos que les serán aclarados en su propia ubicación espacio-temporal. El cine puede resultarnos útil para ejemplificarlo. Además, hemos de presentar a los personajes que, apareciendo en el cuadro, no se mencionan en el capítulo trabajado.

\section{c) Leemos y contamos}

La siguiente tarea consistirá en leer en gran grupo el primer capítulo, titulado "Se abre el taller”. De esta forma, la clase hará un ejercicio de reconstrucción y apreciarán de forma más completa el sentido general de la obra de Fernández Pacheco y su relación con el cuadro de Velázquez. A continuación les invitaremos a leer La Infantita quiere buñuelos, para que aprecien las distintas formas de aproximarse con la literatura a una misma obra pictórica; de igual forma, podrán de manera individual contar una historia la infanta Margarita -al modo de Fernández Pacheco- o crear su propia historia basada en el cuadro -al modo de Asunción Balzola-.

\section{d) Buscamos más Meninas}

Trasladados al aula de ordenadores, entraremos en el siguiente enlace (consultado el I8 de diciembre de 20I2): http://www.ctv.es/USERS/ags/oooII5pi.htm

A través de él accedemos a Las meninas de Picasso, de modo que conozcan a otra de las grandes figuras de la pintura española. Resultará positivo establecer una lluvia de ideas en torno a las semejanzas y diferencias entre ésta y la obra de Velázquez. Una opción posible consiste en hacer pequeños grupos que indaguen sobre el autor vanguardista. 


\section{e) Somos pintores}

Finalmente, de nuevo en la sala de informática, los estudiantes van a jugar a ser pintores. Entraremos en la siguiente página:

http://www.unav.es/digilab/proyectosenl/2004/pintarte/cuentame.htm

(consultada el I7 de diciembre de 20I2), que pertenece al portal "Pintarte". En él encontramos relatos escritos por los internautas de forma espontánea a partir de distintos cuadros. Les daremos la posibilidad de que recreen su propia historia basada en otra obra de Velázquez, por ejemplo. Además, entrarán en la sección “cuaderno de dibujo", donde pintarán su propia adaptación de Las Meninas, con la posibilidad de que el resultado se mantenga grabado en este apartado de la página web.

\section{Segundo Bloque de la propuesta}

\section{a) Debatimos}

Mostramos las láminas con los cuadros de Velázquez, Goya y Murillo -que se incluyen en cada volumen de la colección- para establecer un debate que les lleve a reflexionar sobre los tres modelos de niño que reflejan: la Infanta, el Mendigo y los Niños Populares.

Figura 9. Ficha 1 del docente

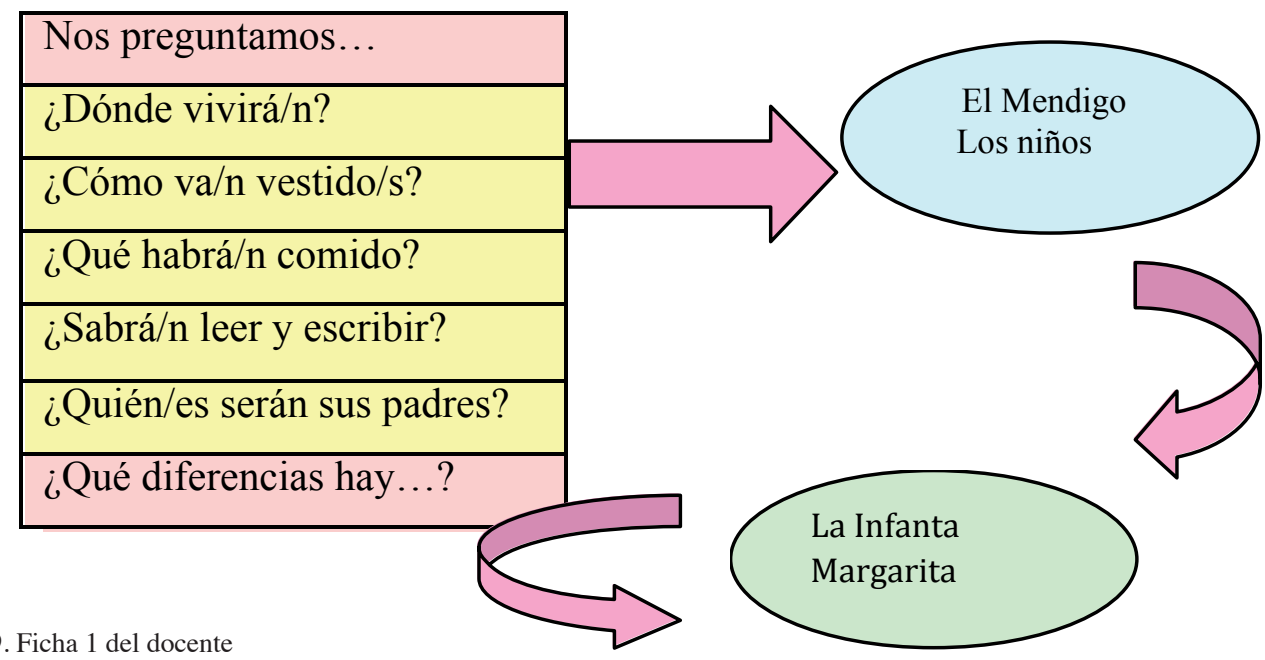

Las anteriores interrogantes nos darán la pauta para guiar las intervenciones de los alumnos, garantizando el uso y desarrollo de habilidades comunicativas diversas:

- Uso de léxico variado y adecuación del registro.

- Elaboración de argumentos sólidos en torno a una idea: coherencia y cohesión textual.

- Marcas pragmáticas: “pensad en”, “como se observa en”, etc.

- Aspectos socio-comunicativos como el respeto al turno de palabra o la postura corporal. 


\section{b) Buscando el original}

Dividiremos al alumnado en dos grupos, a los que asignaremos un relato concreto para su lectura: El perfume envenenado o El niño de las pulgas, de forma que cada título sea trabajado por la mitad de la clase. La tarea consistirá en presentar al equipo contrario la historia creada por Asunción Balzola a través de un juego en el que todos van a ser partícipes. Juntos harán un resumen de la obra y, de forma individual, escribirán, según el ejemplo de la autora, su propio cuento. A continuación, los miembros de cada equipo irán leyendo sus composiciones, entre las que se intercalará el resumen de la auténtica, de manera que al final los miembros del otro grupo se aventuren a identificar cuál es la narración firmada por la escritora vasca. Por último, les aconsejaremos la lectura de ambos originales, a partir de los cuales podremos edificar nuevas actividades.

Para escribir su historia les aportaremos una guía que les oriente al modo siguiente:

\section{FICHA 5}

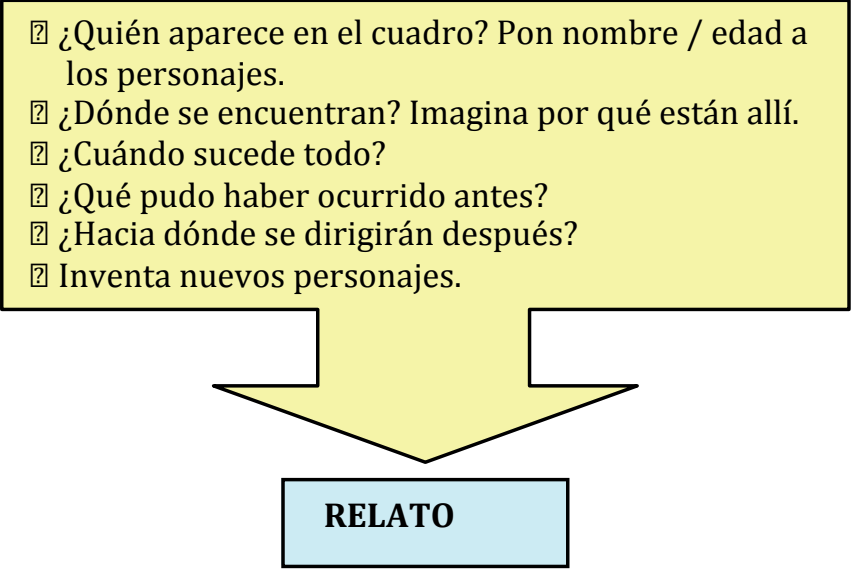

Figura 10. Ficha 5 del docente

Por último, retomaremos el debate inicial para exponer el contraste entre sus primeras impresiones ante la visualización de las imágenes y la lectura detenida de las obras literarias.

\section{c) Lo que indican las palabras}

Sin duda, la lectura de tales textos nos permite realizar otras muchas actividades orientadas al trabajo del léxico y los valores que el devenir sociocultural le ha otorgado en el uso habitual -expresiones y frases hechas-: 

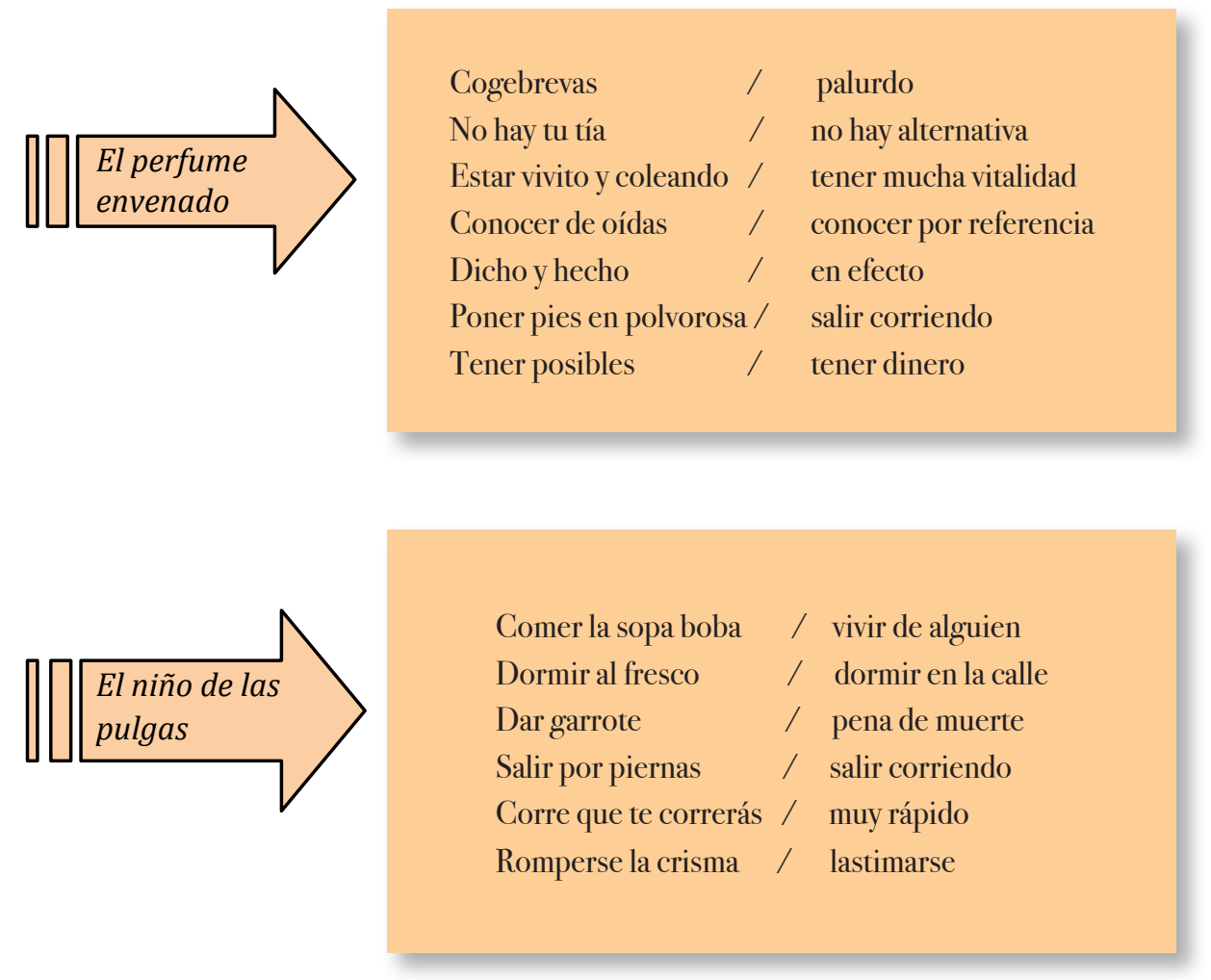

Figura 11. Ficha 2 del docente

Además, todo esto nos ayuda a situarnos en el momento histórico en que los autores desarrollan su labor artística a través de datos que nos hablan de personajes o lugares reales, así como la forma de vida de la época.

\section{El perfume envenenado}

\begin{tabular}{|l|l|}
\hline Referentes & Modos de vida / contexto social \\
\hline - Barrio de Lavapiés & - Una dama y su dueña \\
- Río Manzanares & - Botijo \\
- Manuel Godoy & - Sombrero de ala, manteo al hombro y bastón para andar \\
- Carlos IV & por el monte \\
- Duquesa de Alba & - ¡Una escuela para niñas! ¡Lo que hay que ver! \\
- Sabatini & - Piojos (muy propios en la época) \\
& - Canción de tradición oral: Cucú cantaba la rana \\
& - Profesiones de la época: \\
& - Profesiones propias del momento: \\
& Perfumera, palafrenero, alguacil, aguador y sereno \\
\hline
\end{tabular}




\begin{tabular}{|l|l|}
\cline { 2 - 2 } \multicolumn{1}{c|}{} & \multicolumn{2}{c|}{ El niño de las pulgas } \\
\hline Referentes & \multicolumn{1}{c|}{ Modos de vida / contexto social } \\
\hline \multirow{2}{*}{ - Velázquez } & - Fregar el suelo a cuatro patas \\
- Caravaggio & - La peste (enfermedad propia de la época) \\
- El Papa & - Silla de manos \\
- Río Guadalquivir. & - La vida del pícaro: “Me hacía el cojo. Daba saltos...” \\
- La Indias (Nuevo Mundo) & (pág. I6) \\
- Sevilla & - Descripción de la nobleza de la época: \\
& “Esos señorones de la nobleza que llevan terciopelos y \\
& brocados...” (pág.I9) \\
& \\
\hline
\end{tabular}

Figura 12. Ficha 3 del docente

Todos los datos recogidos en las anteriores tablas nos ayudan a contextualizar el momento en que ambos autores pintan sus obras, e incluso se nos apuntan aspectos que indican el estilo que los caracteriza, especialmente en la obra de Murillo -las alusiones a lo religioso-. Es importante que el profesor sepa aprovechar tales guiños de la autora para ubicar los textos y acercar al alumnado al momento histórico y los artistas españoles. Tal vez podría organizarse a modo de tarea, en la que sean los propios aprendices los agentes activos en todo el proceso de aprendizaje; les damos materiales documentales, páginas web interesantes, revistas sobre arte, etc., para que por sí mismos elaboren un dossier de información sobre cada uno de los tres autores trabajados. De esta forma, cerraremos este período de trabajo con la elaboración de un material que puede permanecer en el aula como elemento de apoyo para otras actividades.

\section{I.3. Materiales y recursos}

- Láminas con reproducciones de las pinturas. Podemos usar las incluidas como anexo en los relatos de Asunción Balzola. De igual forma, se encuentran fácilmente en las siguientes direcciones web (consultadas el I5 de diciembre de 20I2):

* Las meninas (Velázquez), disponible en

http://museoprado.mcu.es/menig.html

http://www.cossio.net/actividades/pinacoteca/p_OI_O2/las_meninas.htm

* Niño espulgándose o Joven mendigo (Murillo), disponible en

http://www.artehistoria.jcyl.es/historia/obras/ıo629.htm

* Niños trepando a un árbol (Goya), disponible en

http://www.cossio.net/actividades/pinacoteca/p_o6_of/ninios_en_la_pintura.htm

*Las meninas (Picasso), disponible en

http://www.ctv.es/USERS/ags/ooom5pi.htm 


\section{- Textos literarios}

* M. Fernández Pacheco (200I). Siete historias para la Infanta Margarita. Madrid: Siruela.

* A. Balzola Eliorza (2003). La Infantita quiere buñuelos. Madrid: S.M.

* A. Balzola Eliorza (2003). El niño de las pulgas. Madrid: S.M.

* A. Balzola Eliorza (2003). Elperfume envenenado. Madrid: S.M.

- Ordenador y conexión a internet.

- Diccionario de la RAE.

- Papel y lápiz.

- Fichas de trabajo (incluidas en la propuesta)

\section{I.4. La evaluación}

Explicitar criterios muy concretos de evaluación en propuestas tan amplias como la expuesta, donde se conjugan muy diversas actividades y destrezas comunicativas no resultaría del todo preciso. Además, son varias las líneas que podrían seguirse para el trabajo en el aula, según la progresión de la propia clase o la elección de los textos literarios para su lectura. De este modo, sería conveniente que el mediador fijara los parámetros en función de los objetivos específicos para cada bloque de tareas, siempre guiados a través de unas pautas centradas en el aprender y formuladas desde una concepción formativa y nunca prescriptiva. Nos servirá de orientación la siguiente tabla con unos indicadores generales:

\begin{tabular}{|l|l|}
\hline INDICADORES & OBSERVACIONES \\
\hline ¿Es capaz de interpretar los textos literarios? & \\
\hline $\begin{array}{l}\text { ¿Relaciona adecuadamente el texto literario } \\
\text { y el pictórico en el transcurso de la propuesta? }\end{array}$ & \\
\hline $\begin{array}{l}\text { ¿Desarrolla las situaciones comunicativas } \\
\text { orales con fluidez y adecuación? }\end{array}$ & \\
\hline $\begin{array}{l}\text { ¿Emplea un uso apropiado de la lengua escrita? } \\
\text { Ortografía, gramática, léxico, presentación, etc }\end{array}$ & \\
\hline $\begin{array}{l}\text { ¿Atiende a las normas pragmáticas y } \\
\text { sociocomunicativas en sus intervenciones? } \\
\text { Registro, pautas de habla, adecuación al } \\
\text { contexto, disposición de ideas, etc. }\end{array}$ & \\
\hline $\begin{array}{l}\text { ¿Demuestra el manejo fluido y apropiado de } \\
\text { marcadores discursivos? }\end{array}$ & \\
\hline
\end{tabular}




\begin{tabular}{|l|l|}
\hline $\begin{array}{l}\text { ¿Ha entrado en contacto de forma efectiva con el } \\
\text { marco cultural tratado a través de la propuesta? }\end{array}$ & \\
\hline $\begin{array}{l}\text { ¿Ha evolucionado en su aprendizaje desde el } \\
\text { inicio? }\end{array}$ & \\
\hline $\begin{array}{l}\text { ¿Manifiesta interés y estímulo hacia el trabajo } \\
\text { en grupo y el autoaprendizaje? }\end{array}$ & \\
\hline $\begin{array}{l}\text { ¿Se beneficia de los recursos TIC ofrecidos } \\
\text { por el docente? }\end{array}$ & \\
\hline Otras cuestiones de interés & \\
\hline
\end{tabular}

Figura 13. Ficha 4 del docente 


\section{Bibliografía}

- Abbate, C. (Ed.) (2002). Música y literatura: estudios comparativos y semiológicos, Madrid, Arco Libros.

- África, Ma .C. y V. Claramente (1992). Arte y literatura: interrelaciones entre la pintura y la literatura del siglo XX. Madrid: Palas Atenea.

- Ambadiang, Th. e I. García (2006). La cultura lingüística y el componente cultural en la enseñanza de lenguas no maternas: observaciones sobre algunos paradigmas de la competencia cultural. Didáctica. Lengua y literatura, I8, 6I-92.

-Ander-Egg, E. (I996). Interdisciplinariedad en educación, Buenos Aires: Magisterio del Río de la Plata.

- Bastons, C. et al (1997). Alfa: mitología, arte, literatura (ESO, Segundo Ciclo). Bloque temático interdisciplinar. Propuesta didáctica. Barcelona: Casals.

- Camarero, J. (2008). Intertextualidd: redes de textos y literaturas transversales en dinámica intercultural, Barcelona, Anthropos, 2008.

- Caro, Ma.T. (1996). La escritura del otro: hacia una reflexión de la literatura como intertextualidad, Murcia, Universidad de Murcia.

- Cassany, D. et al (1994). Enseñar lengua, Barcelona, Graó.

- Dadson, T. y D. W. Flitter (Eds.) (1998). Ludismo e intertextualidad en la lírica española moderna. Birmingham: Servicio de Publicaciones de la Universidad de Birmingham.

- Delgado, R. (2009). La integración de los saberes bajo el enfoque dialéctico globalizador: la interdisciplinariedad y transdisciplinariedad en educación. Investigación y postgrado, 24, $3, \mathrm{II}-44$.

- Durañona, Ma .A. et al. (2006). Textos que dialogan: la intertextualidad como recurso didáctico. Madrid: Dirección General de Promoción Educativa.

- García, F. (r996). Estudios sobre la intertextualidad. Ottawa: Dovehouse Editions Canada. - Genette, G. (ig89). Palimpsestos. La literatura en segundo grado. Madrid: Taurus.

- Guerra, Ma .F. (2003). Una reflexión sobre la interdisciplinariedad en educación. Reflexión académica en diseño y comunicación, IV, 4, 64-65.

- Hansen, H.L. (1998). Diálogo entre Meninas. Arte y literatura como metáforas espaciotemporales en Velázquez y Buero Vallejo. Sociocriticism, Montpellier, 22, I-2.

- Hymes, D. (1962). The ethnography of speaking. En T Gladwin y W.C. Sturtevent (Eds.). Anthropology and human behavior, I3-53. Washington: Anthropological Society of Washington.

- Hymes, D. (1971). Competence and performance in linguistic theory. En Huxley e Ingram (Eds.). Acquisition of languages: Models and methods, 3-23. Nueva York: Academic Press.

- Kristeva, J. (1981). Semiótica I. Madrid: Fundamentos.

- Lara, C. (2007). Las voces y los ecos: perspectivas sobre la intertextualidad. Málaga: Universidad de Málaga.

- Larrosa, J. (I990), Interdisciplinariedad y pedagogía. Barcelona: Publicaciones de la Universidad de Barcelona.

- López-Barajas, E. (1997). Integración de saberes e interdisciplinariedad. Madrid: UNED. 
- Martinell, E., M. Formant y M. Cruz (Coords.) (2004). Cultura e intercultura en la enseñanza del español como lengua extranjera. Barcelona: Facultad de Filología de la Universidad.

- Martínez, J.E. (2OOI). La intertextualidad literaria: base teórica y práctica textual. Madrid: Cátedra.

- Mendoza, A. (2000). Literatura comparada e intertextualidad: una propuesta para la innovación curricular de la literatura (educación secundaria). Madrid: La Muralla.

- Mendoza, A. (2003). Los intertextos: del discurso a la recepción. En A. Mendoza y P. Cerrillo (Coords.). Intertextos: aspectos sobre la recepción del discurso artístico. Cuenca: Ediciones de la Universidad de Castilla-La Mancha.

- Mendoza, A., A. López y E. Martos (i996). Didáctica de la lengua y la literatura para la enseñanza primaria y secundaria. Madrid: Akal.

- Miquel, L. (ז997). Lengua y cultura desde una perspectiva pragmática: algunos ejemplos aplicados al español. Frecuencia L, 5, 3-I4.

- Moormann, E.M. y W. Uitterhoeve (1997). De Acteón a Zeus. Temas sobre la mitología clásica en la literatura, la música, las artes plásticas y el teatro. Madrid: Akal.

- Muñoz, S. (20п). Lengua, cultura y cognición en el aprendizaje de la lengua materna. $S y$ nergies Chili, $7, \mathrm{I} 5-20$.

- Muhsin, I. (2009). La globalidad y la interdisciplinariedad en la educación primaria. Valencia: Cristóbal Serrano.

- Olalla, Ma .A. Y P. Úcar (20Io). Con eñe. Madrid: Universidad Pontificia de Comillas.

- Quiles, Ma . C. (2008). Textos con música: cómo desarrollar las habilidades comunicativas desde una perspectiva interdisciplinar. Glosas Didácticas, 8 (obtenido de http:/ /www. um.es/glosasdidacticas/numeros/GDif/o2.pdf, eli8 de diciembre de 20I2).

- Quiles, Ma .C. (20Iо). La intertextualidad en el aula de español como lengua extranjera. Textos de didáctica de la lengua y la literatura, 54, II3-I23.

- Rubio, J. (2006). Pintura y literatura en G. Adolfo Bécquer. Fundación J.M.Lara.

- Torres, J. (1994). Globalización e interdisciplinariedad: el currículum integrado: Morata.

- Vez, J.M. (2000). Fundamentos lingüísticos en la enseñanza de lenguas extranjeras. Barcelona: Ariel.

- Villalobos, I. (2003). La noción de intertextualidad en Kristeva y Barthes. Revista de filosofía de la Universidad de Costa Rica, XLI, I37-I45. 


\section{Webgrafía}

- Sobre la vida y obra de Francisco de Goya (obtenidas el 20 de noviembre de 20I2):

http://www.fll.vt.edu/Culture-Civ/Spanish/Taller/2oopm/Taller2/

http://www.artehistoria.jcyl.es/genios/pintores/2085.htm

http://goya.unizar.es/InfoGoya/MainMenu.html

http://cvc.cervantes.es/actcult/goya/

http://tierra.free-people.net/artes/pintura-francisco-goya.php

- Sobre la vida y obra de Bartolomé Murillo (obtenidas el 20 de noviembre de 2OI2):

http://www.artehistoria.jcyl.es/genios/pintores/2832.htm http://www.spanisharts.com/history/barroco/barroco_murillo.html http://platea.pntic.mec.es/ $\sim$ anilo/murillo/Murillo.htm http://www.corazones.org/santos/murillopintor.htm

- Sobre la vida y obra de Diego Velázquez (obtenidas el 20 de noviembre de 2OI2):

http://es.wikipedia.org/wiki/Diego_Rodr\%C3\%ADguez_de_Silva_y_Vel\%C3\%Atzquez http://www.artehistoria.jcyl.es/genios/pintores/3652.htm http://www.terra.es/personal/jesus.ru/ http://www.imageandart.com/tutoriales/biografias/velazquez/index.html http://www.casadevelazquez.org/edefault.htm http://cvc.cervantes.es/actcult/museoprado/citas_claroscuro/velazquez/velazquez.htm

- Sobre Asunción Balzola (obtenidas el 20 de noviembre de 2OI2)

http://servicios.elcorreodigital.com/evasion/tendencias/teno3oroogugg.html http://www.fadip.org/?p=42

http://www.amigosdelibro.com/ilustradores/balzola_elorza.htm

- Sobre Eliacer Cansino (obtenidas el 2I de noviembre de 2OI2):

http://es.wikipedia.org/wiki/Eliacer_Cansino

http://www.unilibro.es/find_buy_es/result_scrittori.asp?scrittore=CANSINO\%2C+ELI ACER\&idaff $=0$

http://www.terra.es/personal5/lporras/literaturajuvenil.htm

http://es.geocities.com/r_tintachina/ecansino.htm 